
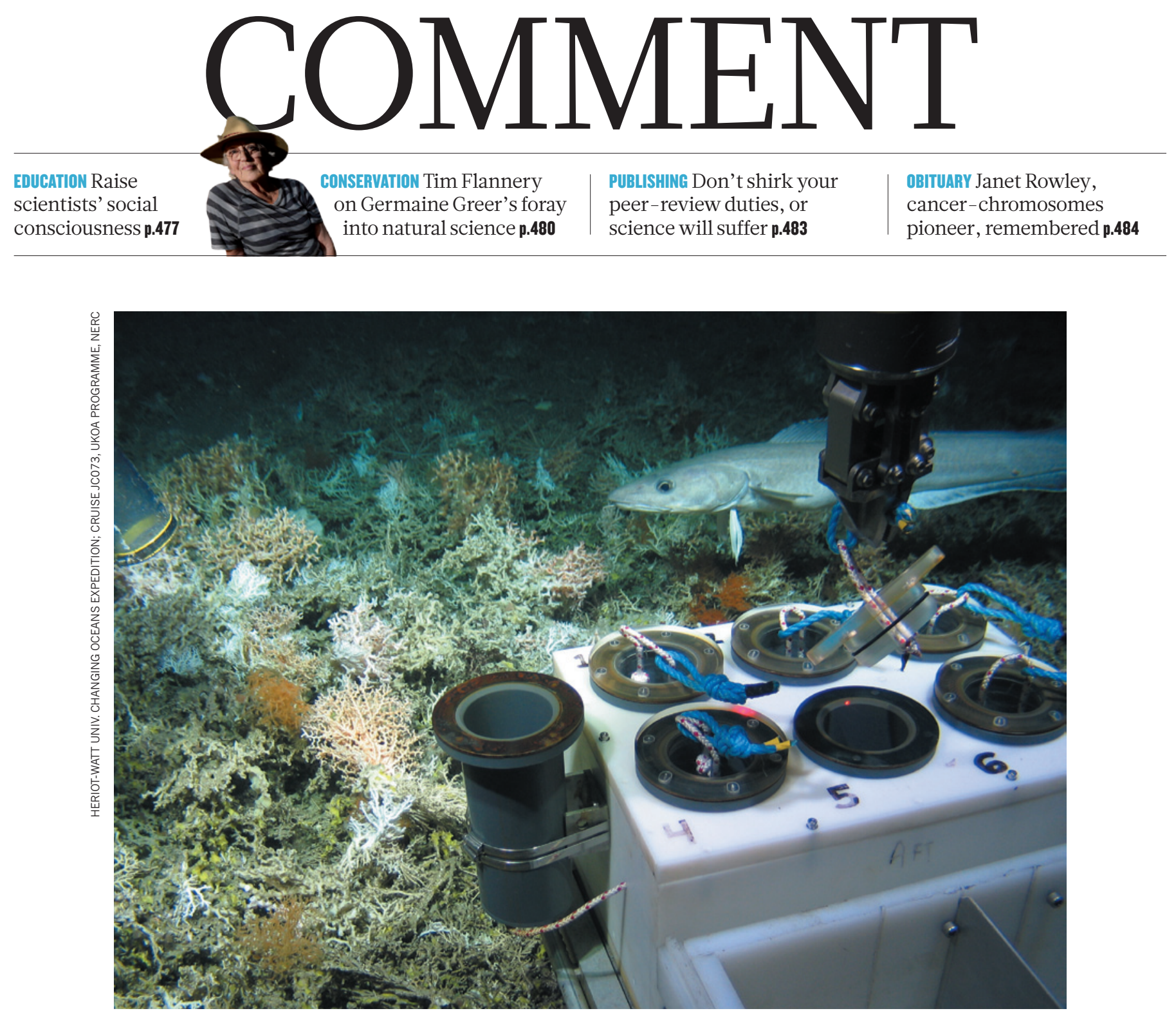

A remotely operated vehicle takes scientific samples on a coral complex in the northeastern Atlantic.

\title{
Protect the deep sea
}

Edward B. Barbier and colleagues call for governance and funds for deep-sea reserves and the restoration of ecosystems damaged by commercial interests.

$\mathrm{M}$ ore than 1 million square kilometres of the sea below 200 metres in depth are being ploughed by trawlers, according to estimates ${ }^{1}$, and the next decade will see expansion of oil, gas and mineral extraction into deeper and deeper waters ${ }^{2}$ (see go.nature.com/brhbll). At risk are ecosystems that contribute to the health and productivity of the ocean, that challenge our ideas of the extremes at which life can exist (such as hydrothermal vents), and that are habitats and nurseries for fisheries (seamounts, for example). Our knowledge of deep-ocean biodiversity only hints at thousands of undiscovered organisms and their benefits. Some threatened species, such as cold-water corals, have lifespans of hundreds or even thousands of years; habitats, including rock concretions called manganese nodule beds, can take millennia to form.

We call for formal governance structures and funds to be put in place by 2020 to create networks of deep-sea reserves that maintain and restore biodiversity and function in this vast and important biome ${ }^{3}$. To support these efforts, a global strategy must be framed under the aegis of national governments and an international body. For areas that are beyond national jurisdiction, the International Seabed Authority (ISA) is best suited to this task.

\section{COSTS AND BENEFITS}

Deep-sea restoration experiments have already begun. Cold-water corals from the northeastern Atlantic survive and grow in laboratories ${ }^{4}$ and experimental reintroduction to the sea floor has proved successful, with $76 \%$ of corals surviving after three 
years ${ }^{5}$. Efforts are ongoing in the United Kingdom to develop 'coralbots', swarms of autonomous undersea vehicles to transplant and monitor coral fragments in the deep sea to overcome fishing damage.

But the potential effectiveness of largescale restoration is unknown, and the precedents are not promising: after almost four decades of restoration, freshwater and coastal ecosystems still do not recover their full biodiversity and functionality. Repairing damage to and enhancing recovery of deep-sea ecosystems will be more expensive than for shallow ones by two to three orders of magnitude. For example, it could cost as much as US\$75 million to restore one hectare of trawled seabed at the Darwin

Mounds hummocks inhabited by corals at a depth of one kilometre in the Rockall Trough of the northeastern Atlantic ${ }^{3}$.

It is a price that many feel is worth paying. As well as oil, gas, mineral and biomedical resources, deep-sea ecosystems have other important functions, including roles in gas and climate regulation, and waste absorption and detoxification ${ }^{6}$.

A 2007 study $^{7}$ revealed that the public in Ireland is willing to pay up to $€ 10(\$ 14)$ per person to protect deep-sea corals from trawling so that the corals can provide raw materials for the biomedical industry, essential fish habitats and carbon sinks. Visitors and residents in the Azores, an Atlantic archipelago about 1,500 kilometres west of Portugal, expressed a willingness to pay €405-605 per person ${ }^{8}$ to prevent $10-25 \%$ reductions in marine species richness in open waters, including the deep sea. In Scotland, survey ${ }^{6}$ respondents were willing to pay $£ 70$ (\$115) to $£ 77$ each to promote maximum deep-sea biodiversity conservation and develop new medicinal products from deep-sea species.

\section{A GLOBAL STRATEGY}

A key feature of a global strategy for protecting and restoring the deep sea should be the 'polluter pays' principle. That is, stakeholders who are most responsible for damages should fund deep-sea ecosystem reserves, research and restoration. These entities are likely to include mining, oil and gas, transportation and fishing companies.

However, implementation of this strategy will depend on whether the deep sea lies inside or outside national boundaries. For areas within national jurisdiction, the responsibility for restoration, protection and determining liability would fall on individual states. Governance in areas beyond national jurisdiction, where most of the deep sea lies, is currently divided according to sectorial activities - primarily fishing, shipping and mining. Because a universal authority to consider ecosystem protection, costs and benefits in international waters does not yet exist, adding a biodiversity-conservation agreement to the United Nations Convention on the Law of the Sea (UNCLOS) is under discussion, with a decision due in late 2015. Such a development is an essential first step for protecting the deep sea.

An important component of the 2015 UN General Assembly decision should be to either develop a new body to protect deepsea biodiversity, or to extend the mandate of the ISA beyond mining to protect habitats from a wider range of regulated commercial industrial activities.

A key role of the Convention on Biological Diversity (CBD) is to provide scientific and technical advice to states and relevant authorities, so a close cooperation between the CBD and the ISA could be established even during such negotiations. This cooperation could apply the CBD's targets, which call for protecting and restoring $10 \%$ of the oceans, including the deep sea, by 2020 .

\section{RESTORATION FUND}

To implement the updated UNCLOS agreement, a new fund of around \$30 million per annum, perhaps managed by the ISA, is needed to cover conservation and restoration research, development and implementation for the deep sea in areas beyond national jurisdiction. This fund should start immediately after the 2015 decision, and comprise contributions from the national or private companies that undertake mining, transportation, fishing and other commercial activities that are harmful to sea-floor ecosystems. The ISA is charged with granting licences for deep-sea mining in the high seas and with sharing a proportion of the profits with the international community, primarily developing states. The fishing industry, by contrast, is accustomed to free access to deep-sea resources and is reluctant to pay for restoring seabed ecosystems affected by trawling ${ }^{3}$.

A tax is an alternative to voluntary contributions. For example, the total catch value from high seas bottom trawling (HSBT) is $\$ 601$ million per year for the 12 countries with major fleets ${ }^{9}$. A $1 \%$ tax on these revenues could raise $\$ 6$ million annually (4\% of the $\$ 152$ million in subsidies that these countries currently give their HSBT fleets $\left.{ }^{9}\right)$. Current deep-water oil production (which is within national boundaries) is estimated at 5 million to 6.3 million barrels a day ${ }^{10}$. If states agreed, at current world prices of about $\$ 100$ per barrel, a $1 \%$ royalty would generate between $\$ 5$ million and $\$ 6.3$ million a day.

Another alternative is an international finance facility, which would mobilize resources for deep-sea restoration from international capital markets by issuing long-term bonds to be repaid by donor countries over 20-30 years. For instance, the International Finance Facility for Immunisation (IFFIm) was launched in 2006 to provide funds for vaccinations, and it has so far received pledges of $\$ 6.3$ billion for 23 years from nine donor countries (see www.iffim.org). A proposed Global Forest Finance Facility, based on the IFFIm, could serve as a model for a deep-sea finance facility.

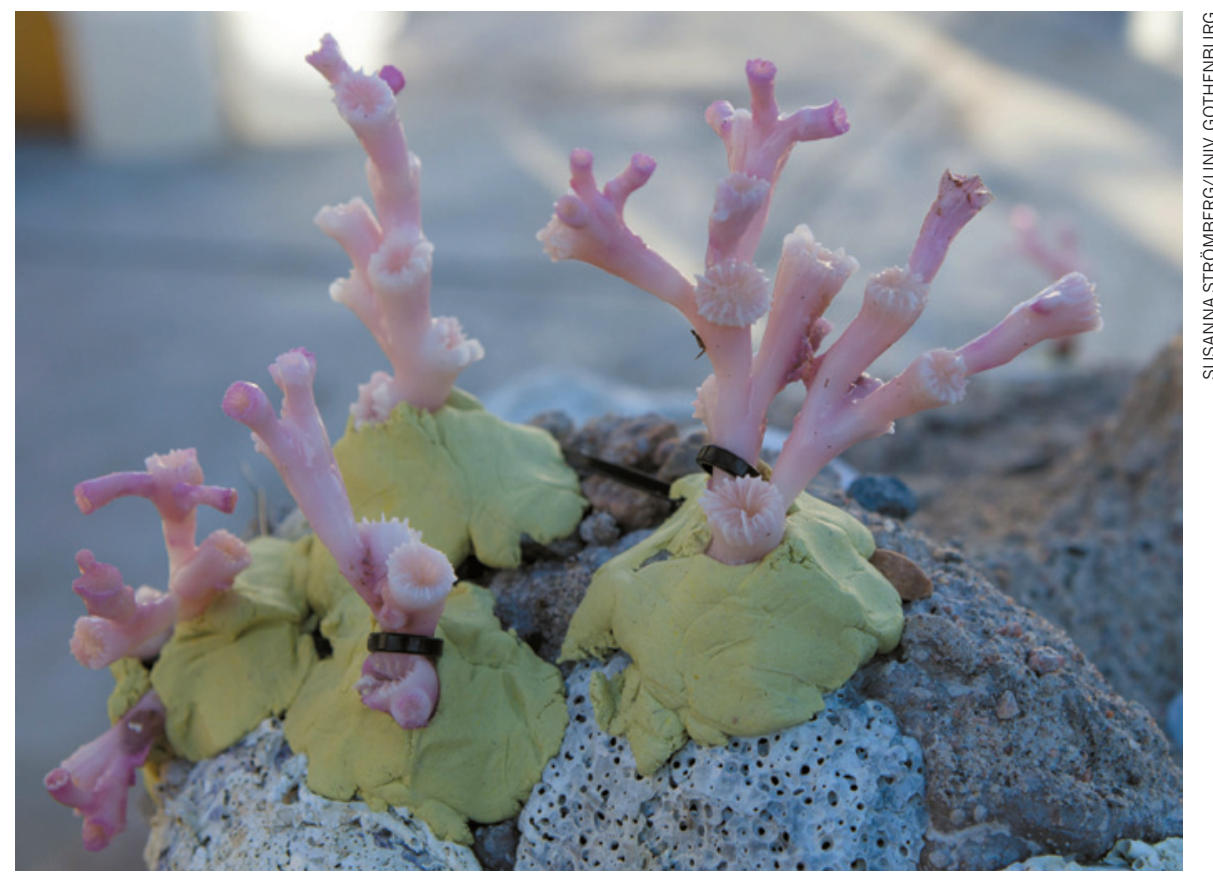

Coral (Lophelia pertusa) mounted on artificial reefs before use in restoration efforts near Sweden. 
National governments, the international community and commercial interests should agree by 2015 on which mechanisms would work best to finance $\sum$ deep-sea protection and restoration, and by 2020 , cooperate on implementing the fund. If we wish to continue to enjoy the benefits of deep-sea ecosystems, it is essential that we find ways to finance deep-sea research, reserves and restoration.

Edward B. Barbier is professor of economics at the University of Wyoming, Laramie. David Moreno-Mateos is at the CNRS Centre of Evolutionary and Functional Ecology, Montpellier, France. Alex D. Rogers is in the Department of Zoology, University of Oxford, UK. James Aronson is at the CNRS Centre of Evolutionary and Functional Ecology, Montpellier, France, and at the Missouri Botanical Garden, St Louis, Missouri.

Linwood Pendleton is senior fellow in the Ocean and Coastal Policy Program, Nicholas Institute for Environmental Policy Solutions, Duke University, Durham, North Carolina. Roberto Danovaro is in the Department of Life and Environmental Sciences, Polytechnic University of Marche, Ancona, Italy, and at the Anton Dohrn Zoological Station, Naples, Italy. Lea-Anne Henry is at the Centre for Marine Biodiversity and Biotechnology, School of Life Sciences, Heriot-Watt University, Edinburgh, UK. Telmo Morato is at the Institute of Marine Research in the Department of Oceanography and Fisheries, University of the Azores, Horta, Portugal, and at the Laboratory for Robotics and Systems in Engineering and Science, Portugal. Jeff Ardron is at the Institute for Advanced Sustainability Studies, Potsdam, Germany. Cindy L. Van Dover is in the Division of Marine Science and Conservation, Nicholas School of the Environment, Duke University, Beaufort, North Carolina. e-mail:ebarbier@uwyo.edu

1. Priede, I. G. et al. ICES J. Mar. Sci. 68, 281-289 (2011).

2. Van Dover, C. L. Nature 470, 31-33 (2011).

3. Van Dover, C. L. et al. Mar. Policy 44, 98-106 (2013).

4. Strömberg, S. M., Lundälv, T. \& Goreau, T. J. J. Exp. Mar. Bio. Ecol. 395, 153-161 (2010).

5. Dahl, M. Conservation genetics of Lophelia pertusa. PhD Thesis, Paper V. Univ. Gothenburg (2013).

6. Jobstvogt, N., Hanley, N., Hynes, S., Kenter, J. \& Witte, U. Ecol. Econ. 97, 10-19 (2014).

7. Wattage, P. et al. Fish. Res. 107, 59-67 (2011).

8. Ressurreição, A. et al. Ecol. Econ. 70, 729-739 (2011).

9. Sumaila, U. R. et al. Mar. Policy 34, 495-497 (2010).

10.Sandrea, R. \& Sandrea, I. Oil Gas J. 108, 48-53 (2010).

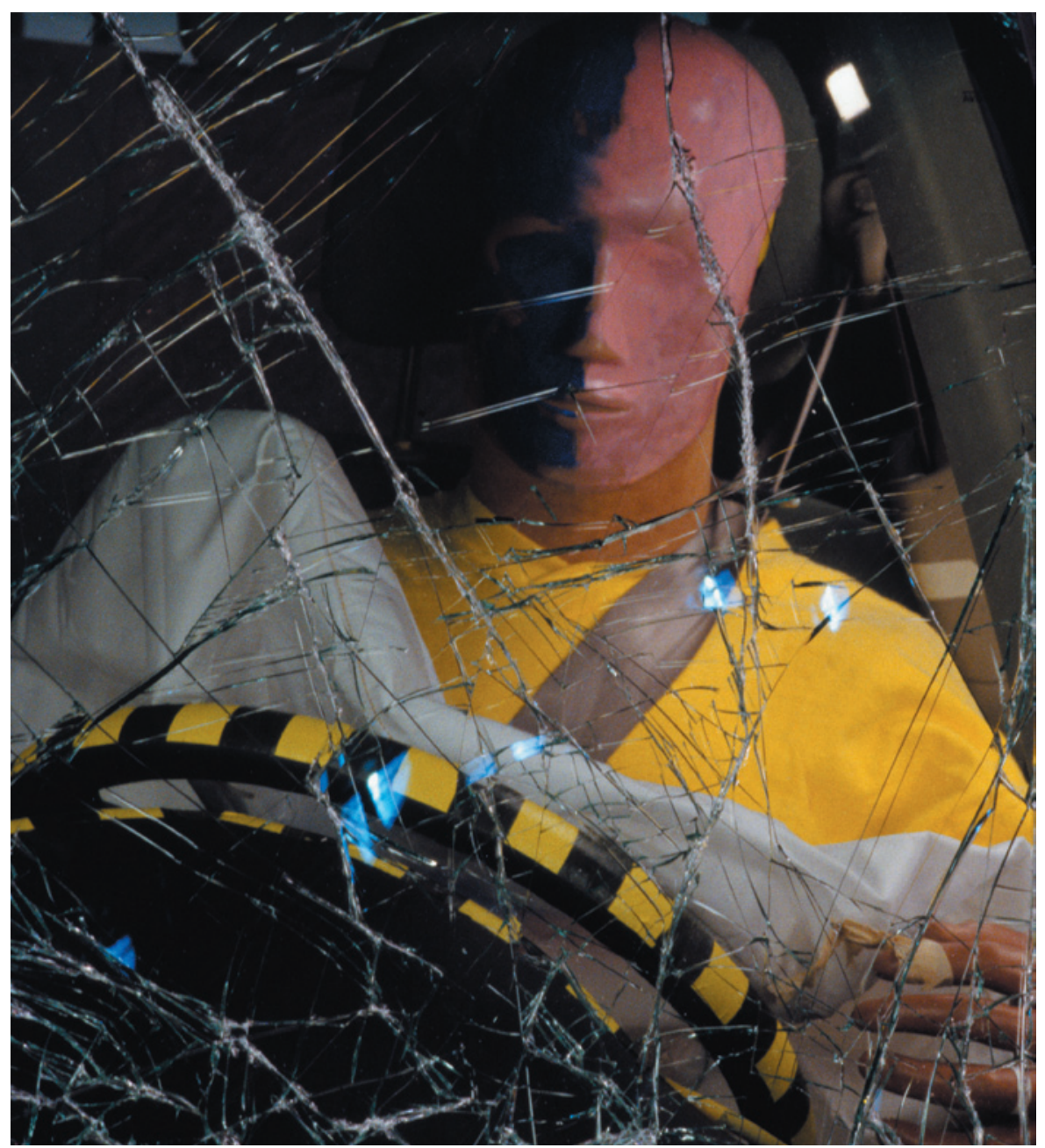

Early airbags were dangerous to women and children, having been designed for adult men.

\title{
Embed social awareness in science curricula
}

\author{
Separate ethics courses are not enough, argues
}

Erin A. Cech. Understanding the public-welfare impacts of science and engineering is a core professional skill.

$\mathrm{A}$ s a social scientist who is also trained as an engineer, I am puzzled by how often public-welfare and socialjustice issues are viewed as irrelevant or tangential to 'real' technical work in science, technology, engineering and mathematics (STEM) professions. I carried out a study ${ }^{1}$, the results of which suggest that university education exacerbates this culture of disengagement.

Between 2003 and 2008, I surveyed a total of more than 300 engineering students in four US universities - a large state college, an elite technical college, a small engineering-only university and a small private liberal-arts college. Following students from their first year to 18 months after their graduation, I found that, on average, they left their degrees less interested in public welfare than when they began.

The reverse should be true. STEM practitioners and educators increasingly recognize that those who understand the role of their profession in society are better at solving real-world problems ${ }^{2}$. Ethics courses for STEM students are proliferating. But adding a few courses is not enough. Social issues should be embedded throughout STEM curricula. Scientists and engineers must view the understanding of the social context 